\title{
The devil is in the detail: estimating species richness, density, and relative abundance of tropical island herpetofauna
}

\author{
Harikrishnan Surendran ${ }^{1}$ and Karthikeyan Vasudevan ${ }^{1,2^{*}}$
}

\begin{abstract}
Background: One of the basic premises of drawing samples from populations is that the samples are representative of the populations. However, error in sampling is poorly recognized, and it goes unnoticed especially in community ecology. By combining traditional open quadrats used for sampling forest floor herpetofauna with intensive bounded quadrats, we explore the effect of sampling error on estimates of species richness, diversity, and density in the Andaman Islands.
\end{abstract}

Results: Fisher's $\alpha$ measure of species diversity and second order jackknife estimate of species richness were not sensitive to number of individuals sampled. Sampling error resulted in underestimation of density in both frogs and lizards. It influenced relative abundance of individual species resulting in underestimation of abundance of small or camouflaged species; and also resulted in low precision in lizard species richness estimates.

Conclusions: Sampling error resulted in underestimation of abundance of small, fossorial or camouflaged species. Imperfect detection from less intensive sampling method results incorrect estimates of abundance of herpetofauna. Fisher's $\alpha$ for species diversity and second order jackknife for species richness were robust measures. These have strong implications on inferences made from previous studies as well as sampling strategies for future studies. It is essential that these shortfalls are accounted for while communities are sampled or when datasets are compared.

Keywords: Rainforest, Lizards, Frogs, Precision, Relative bias, Population density, Tropical islands

\section{Background}

Conservation biologists are constantly faced with a conflict of interests: on the one hand, they need information on population abundance, species richness etc. for implementing conservation programs; while on the other, they should be cautious on reliability of findings from published work [1]. 'Additional surveys' is the most often sought after option in order to fill the gaps in knowledge. Since this is often not feasible due to limited resources, robustness of inventory is a desirable attribute of any faunal survey [2]. Robustness depends on unbiased and precise measurements of parameters that describe

\footnotetext{
*Correspondence: karthik@ccmb.res.in

2 Present Address: Laboratory for Conservation of Endangered Species, CSIR-Centre for Cellular and Molecular Biology, Pillar 162, PVNR Expressway, Hyderguda, Hyderabad 500048, Telangana, India Full list of author information is available at the end of the article
}

the biological community. However, it is a well known fact that biases in sampling are common and sampling assumptions are not always met with [3].

Since most empirical studies in community ecology use some form of sampling to derive estimates of species richness, diversity, and abundance, the properties of these samples have great practical importance [4]. Particularly, when the inventory of a community is based on a non-random fraction of a population, it results in sampling error, which precludes direct comparisons of population size and species diversity measures across studies. To address this, some fundamental questions about survey methods need to be answered: how are bias and precision of estimates of diversity and abundance related to survey methods and effort? How do they affect our interpretation of estimates of population sizes and subsequent conservation decisions? Answering these questions and 

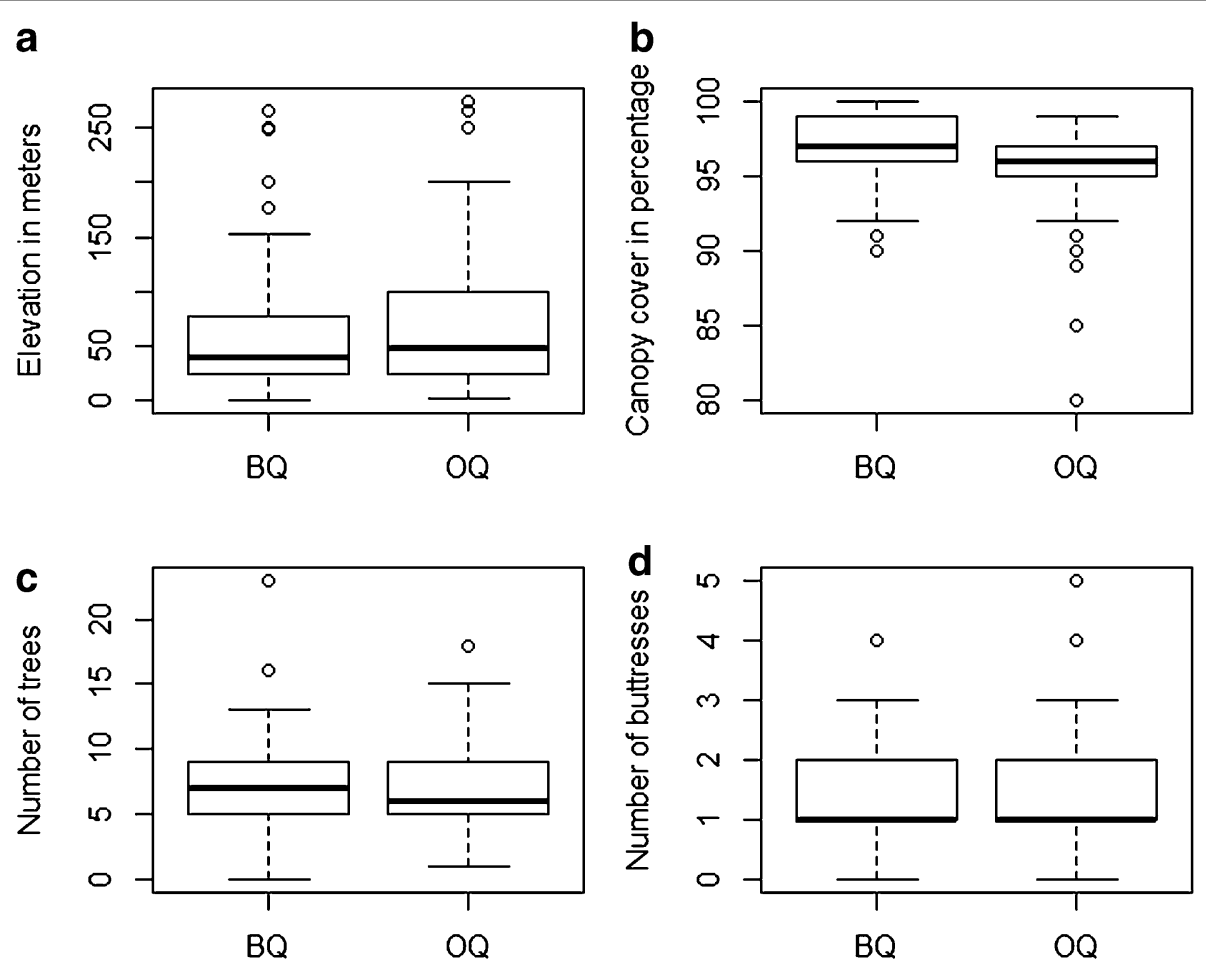

Figure 1 Variation in environmental variables between open and bounded quadrats $\mathbf{a}$ Elevation $\mathbf{b}$ Canopy cover $\mathbf{c}$ Number of tress $\mathbf{d}$ Number of buttresses.

overcoming the problems in sampling are central to good-practice in data collection and study design.

We illustrate this problem using a small tropical island herpetofauna. Small island fauna compose of a finite community and they could be sampled using quadrat sampling with varying levels of intensity. Several studies in the tropics have used quadrats as sampling units to document patterns in species richness, distribution, and abundance of forest-floor herpetofauna [5-18]. Most of these studies have assumed that they recorded all individuals and species in the quadrats during sampling, i.e. no sampling error, which is a major assumption (but see [13, $14,19])$. We explored the effect of sampling error on species richness, diversity, and density estimates from such 'open quadrats' (OQ) by combining them with 'bounded quadrats' (BQ) that gave total counts of individuals in the sampled area [13]. Our study revealed that intensive sampling using $B Q$ had varying effects on species richness and diversity, depending on the estimator, while it significantly improved density estimates.

\section{Results}

\section{Effect of quadrat characteristics}

Boxplots of environmental variables showed no major difference between $\mathrm{OQ}$ and $\mathrm{BQ}$ (Figure 1). Further, ANCOVA indicated quadrat type to be the most significant factor explaining the variation in number of individuals (lizards-residual standard error $=8.29$ on 191 degrees of freedom (DF), multiple $R^{2}=0.24$, adjusted $R^{2}=0.21, F=8.65$ on 7 and $191 \mathrm{DF}, p=3.31 \times 10^{-09}$; frogs - residual standard error $=4.95$ on $185 \mathrm{DF}$, multiple $R^{2}=0.22$, adjusted $R^{2}=0.19, F=8.65$ on 7 and 185 DF, $p=6.02 \times 10^{-08}$; Table 1). Canopy cover also influenced number of both lizards and frogs recorded. Number of buttressed trees and number of trees influenced abundance of lizards and frogs respectively. In general, habitat characteristics did not overwhelmingly influence abundance of frogs and lizards recorded in quadrats.

\section{Species richness}

Observed species richness, of both lizards and frogs, were similar in BQ and OQ (Table 2). For both lizards and frogs, Chao1 estimators were significantly different between $\mathrm{OQ}$ and $\mathrm{BQ}$ for both lizards $\left(t=9.90, \mathrm{df}=46, P<1.0 \times 10^{-5}\right)$ and frogs $(t=3.57$, $\mathrm{df}=41, P=9.29 \times 10^{-4}$ ). Fisher's $\alpha$ was also different between OQ and BQ for both lizards $(t=5.18$, $\left.\mathrm{df}=756, P<1.0 \times 10^{-5}\right)$ and frogs $(t=-4.11, \mathrm{df}=187$, $\left.P=5.8 \times 10^{-5}\right)$. Second order jackknife estimate was not influenced by sampling methods i.e., the way individuals were included in the samples (Table 1). Species richness of both frogs and lizards were correlated with 
Table 1 Analysis of covariance table for number of individuals recorded in quadrats with number of individuals of lizards and frogs as the independent variable and quadrat type, forest type, elevation, number of trees, canopy cover and number of tree buttresses as predictor variables

\begin{tabular}{lrrrrl}
\hline & DF & \multicolumn{1}{l}{ SS } & \multicolumn{1}{l}{ MS } & \multicolumn{1}{l}{ F } & Pr(>F) \\
\hline Lizards & & & & & \\
Quadrat type & 1 & $3,151.70$ & $3,151.70$ & 45.89 & $1.51 \times 10^{-10}$ \\
Forest type & 2 & 52.90 & 26.46 & 0.39 & 0.68 \\
Elevation & 1 & 26.60 & 26.60 & 0.39 & 0.51 \\
Trees & 1 & 14.80 & 14.75 & 0.22 & 0.64 \\
Canopy cover & 1 & 375.00 & 374.99 & 5.46 & 0.02 \\
Buttress & 1 & 536.50 & 536.49 & 7.81 & 0.01 \\
Residuals & 191 & $13,118.00$ & 68.68 & & \\
Frogs & & & & & \\
Quadrat type & 1 & 869.60 & 869.60 & 35.46 & $1.28 \times 10^{-08}$ \\
Forest type & 2 & 34.90 & 17.46 & 0.71 & 0.49 \\
Elevation & 1 & 34.40 & 34.36 & 1.40 & 0.24 \\
Trees & 1 & 163.00 & 163.01 & 6.65 & 0.01 \\
Canopy cover & 1 & 159.20 & 159.16 & 6.49 & 0.01 \\
Buttress & 1 & 26.60 & 26.58 & 1.08 & 0.30 \\
Residuals & 185 & $4,536.40$ & 24.52 & & \\
\hline
\end{tabular}

sampling effort in BQ (Pearson's product-moment correlation, frogs $r=0.58, t=4.87, P=1.30 \times 10^{-05}$; lizards, $r=0.54, t=4.38, P=6.68 \times 10^{-05}$; Figure $2 \mathrm{~b}, \mathrm{~d}$ but not in OQ (frogs, $r=0.08, t=0.99, P=0.33$; lizards, $r=0.04, t=0.52, P=0.60$; Figure 2a, c). Abundances of frogs and lizards were not correlated with sampling effort in both the methods (Figure 3). Accumulation of rare species in samples (singletons) was faster for frogs and lizards in BQ than in OQ (Figure 4).

\section{Density and relative abundance}

We detected 757 lizards and 302 frogs in 49 and 42 BQ respectively. From $151 \mathrm{OQ}$, we detected 929 lizards and 188 frogs. When the variance was adjusted for sample size difference, density estimates from $B Q$ were significantly greater than that from $O Q$ for both lizards and frogs (Wilcoxon-Mann-Whitney test, lizards, $\mathrm{W}=5,209, P=1.67 \times 10^{-5}$; frogs, $\mathrm{W}=4,165$, $P=1.09 \times 10^{-4}$ ). In the case of lizards, the density estimate from $B Q$ was more than twice that from $O Q$ (Table 2). In the case of frogs, density estimate from BQ was more than seven times that from OQ (Table 2). However, the effort involved in a BQ was significantly more $(16.75 \pm 4.02$ man-hours $)$ than that for an $\mathrm{OQ}$ (3.39 \pm 0.97 man-hours; Wilcoxon-Mann-Whitney test, $\mathrm{W}=4,832, P<2.2 \times 10^{-16}$ ).

There was a noticeable difference in the relative abundance of some species between the two methods. Among lizards, the small, fossorial species Lygosoma bowringii showed the greatest increase in relative abundance within $\mathrm{BQ}$, while the larger and more conspicuous Coryphophylax subcristatus and Eutropis andamanensis had greater relative abundance in OQ (Figure 5). Among frogs, the small leaf-litter dwelling Limnonectes cf. doriae had greater relative abundance in bounded quadrats, while the arboreal and brightly coloured Ingerana charlesdarwini had greater relative abundance in $\mathrm{OQ}$ than in $\mathrm{BQ}$ (Figure 5).

\section{Relative bias and precision}

Density estimates obtained from OQ had high relative bias and low relative precision for both lizards (relative bias $=-0.40$, relative precision $=0.51$ ) and frogs (relative bias $=-0.74$, relative precision $=0.33$ ). Second order jackknife estimate of species richness had low relative bias for frogs $(-0.02)$ and lizards $(-0.01)$. The relative precision of the estimate for lizards was also low (1.26) and in frogs it was high (0.06). Species diversity estimated as Fisher's $\alpha$, of frogs and lizards, the relative bias and relative precision ranged from -0.02 to 0.03 , implying no difference in the efficiency of the methods for this parameter.

\section{Conclusions}

Stemming rapid loss of biodiversity in the tropics requires robust scientific findings that bolster conservation decisions. It is up to the field biologists to ensure

Table 2 Summary of analysis of species richness and density using bounded quadrats and open quadrats

\begin{tabular}{|c|c|c|c|c|c|c|c|c|c|c|c|}
\hline \multicolumn{7}{|c|}{ Bounded quadrats } & \multicolumn{5}{|c|}{ Open quadrats } \\
\hline & $\mathrm{n}$ & $\mathrm{S}_{\mathrm{obs}}$ & $\mathrm{S}_{\text {Chao1 }}$ & $\mathrm{S}_{\text {Jack2 }}$ & $\alpha$ & D & $\mathrm{S}_{\text {obs }}$ & $\mathrm{S}_{\text {Chao1 }}$ & $\mathrm{S}_{\text {Jack2 }}$ & $\alpha$ & D \\
\hline Lizards & 47 & 7 & $7 \pm 0.03$ & $6.99 \pm 0.09$ & $1.07 \pm 0.15$ & $15.45 \pm 15.55$ & 7 & $6.32 \pm 0.47$ & $6.86 \pm 1.64$ & $1.03 \pm 0.15$ & $6.15 \pm 4.09$ \\
\hline Frogs & 42 & 8 & $7.62 \pm 1.58$ & $7.95 \pm 2.5$ & $1.25 \pm 0.23$ & $7.19 \pm 10.24$ & 7 & $6.19 \pm 2.06$ & $7.53 \pm 2.84$ & $1.35 \pm 0.24$ & $1.31 \pm 10.24$ \\
\hline
\end{tabular}

Though 49 bounded quadrats were sampled, for the purpose of comparison of estimated species richness, we use a sample size of 47 for lizards because beyond this, the standard deviation of the estimated species richness became zero for jackknife2 estimate. Estimated species richness of frogs is compared at a sample size of 42 as the remaining 7 bounded quadrats were in small islands where no amphibian has ever been recorded. Fisher's $\alpha$ is compared at a common number of individuals (757 lizards and 188 frogs). The standard deviations for density estimates presented here are unadjusted for sample size difference.

$n$ number of quadrats based on which the estimates were arrived at, $S_{\text {obs }}$ observed species richness, $S_{\text {Chao } 1}$ Chao 1 estimate, $S_{\text {Jack2 }}$ second order jackknife estimate, $\alpha$ Fisher's alpha, $D$ density (individuals $/ 100 \mathrm{~m}^{2}$ ). 

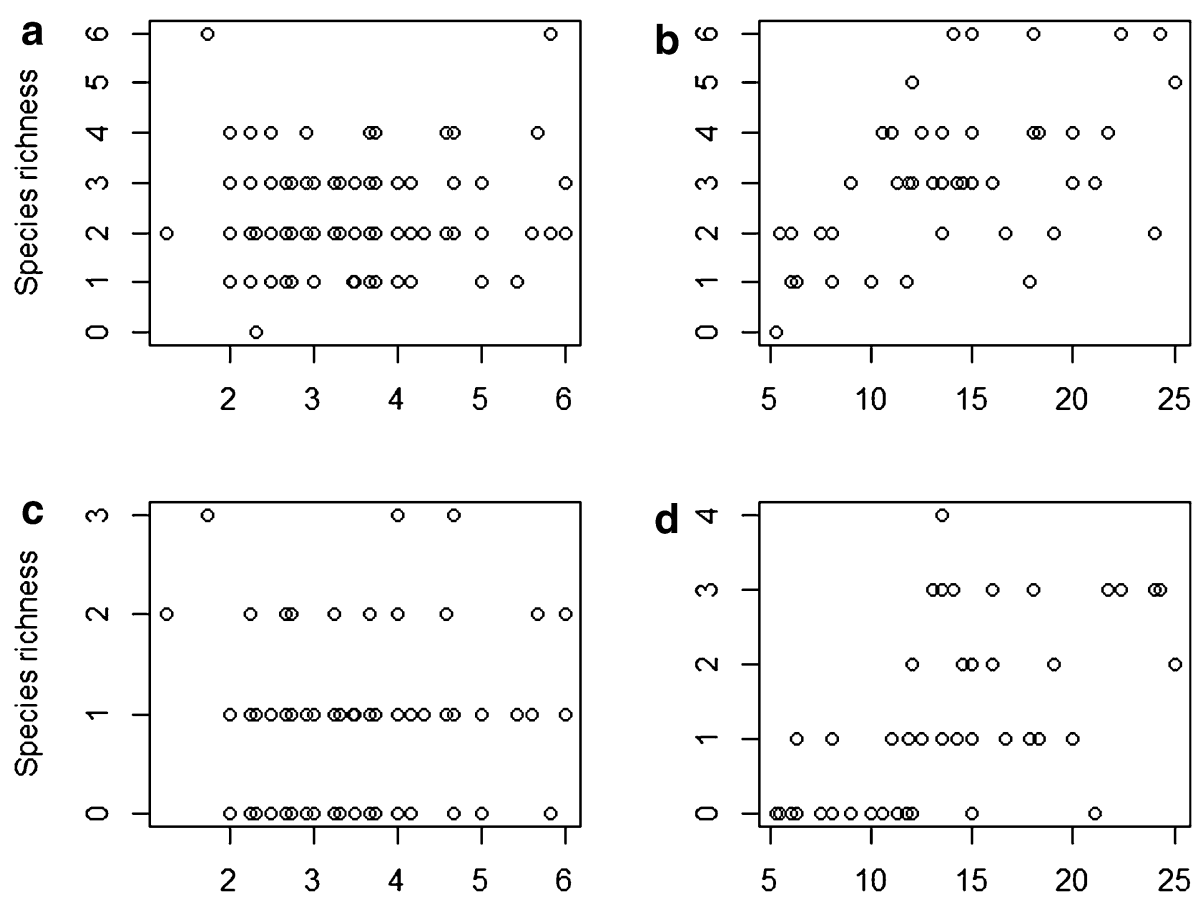

Sampling effort (Man-hours)

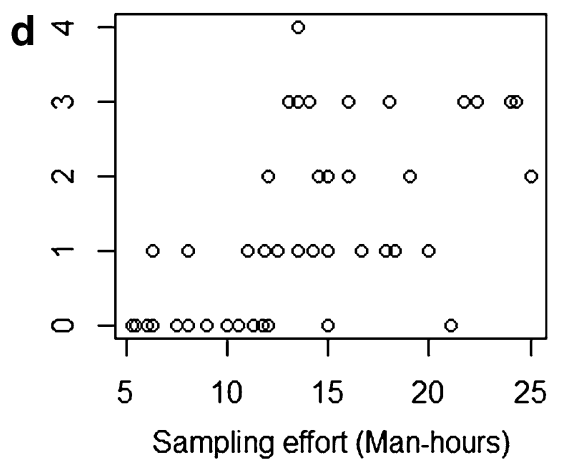

Figure 2 Relationship between sampling effort and species richness a Lizards in $\mathrm{OQ} \mathbf{b}$ Lizards in $\mathrm{BQ} \mathbf{c}$ Frogs in $\mathrm{OQ} \mathbf{d}$ Frogs in $\mathrm{BQ}$.
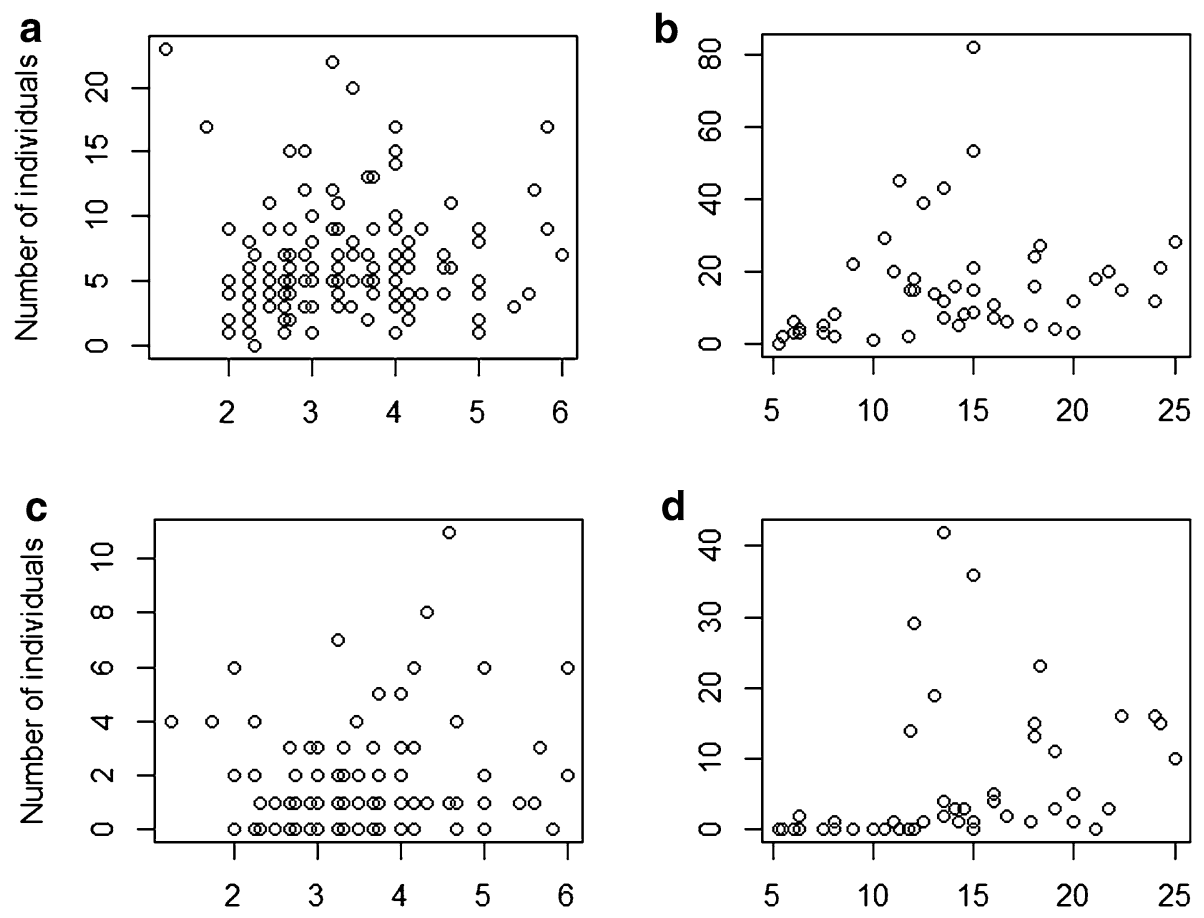

Sampling effort (Man-hours)

Sampling effort (Man-hours)

Figure 3 Relationship between sampling effort and abundance $\mathbf{a}$ Lizards in $\mathrm{OQ} \mathbf{b}$ Lizards in $\mathrm{BQ} \mathbf{c}$ Frogs in $\mathrm{OQ} \mathbf{d}$ Frogs in $\mathrm{BQ}$. 


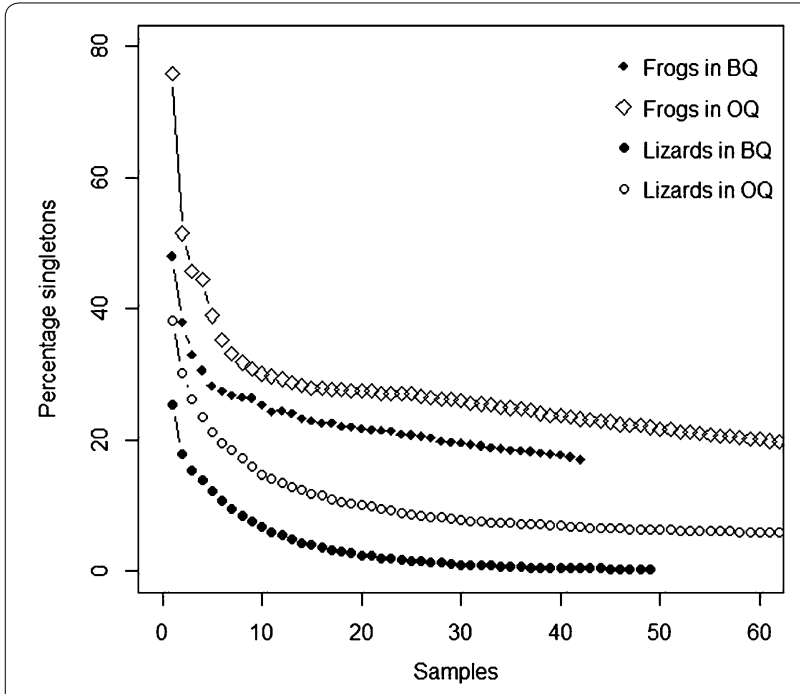

Figure 4 Detection of rare species in the community expressed as reduction in percentage of singletons against sample size for frogs and lizards in open and bounded quadrats. Solid diamonds frogs in $\mathrm{BQ}$, open diamonds frogs in $\mathrm{OQ}$, solid circles lizards in $\mathrm{BQ}$, open circles lizards in $\mathrm{OQ}$.

that the results provided are accurate so that decisions on resource utilization and management are not based on biased or imprecise results. In most community studies on herpetofauna, sampling methods are chosen arbitrarily, as a result, little attention has been paid to the effect of sampling error and its implications on inferences drawn [13, 20-23]. Recently, Kellner and Swihart [20] showed that $77 \%$ of ecological studies ignored imperfect detection, while the rest accounted for this through estimation of detection probability through statistical modelling. A majority of studies (86\%) also reported detection probability to be highly variable, inflating the error in estimated parameters [20]. Our study showed that sampling error in open quadrats resulted in bias in estimated population density and in detection of less conspicuous and small frogs and lizards. Open quadrats have often been used repeatedly for sampling forest floor herpetofauna and these studies report accurate estimates of density from such plots. However, Rodda et al. [13, 19] reported high densities of reptiles using their 'total removal plots', which is a form of bounded quadrat. Bounded quadrats have invariably reported high densities of herpetofauna $[13,21,24-26]$. Our data revealed that bounded quadrats are efficient in sampling rare species and we expect that its performance will be better in tropical mainland areas than in islands, where a large proportion of the community is composed of rare species. This study provides empirical evidence for second order jackknife estimate for species richness and Fisher's $\alpha$ for diversity as

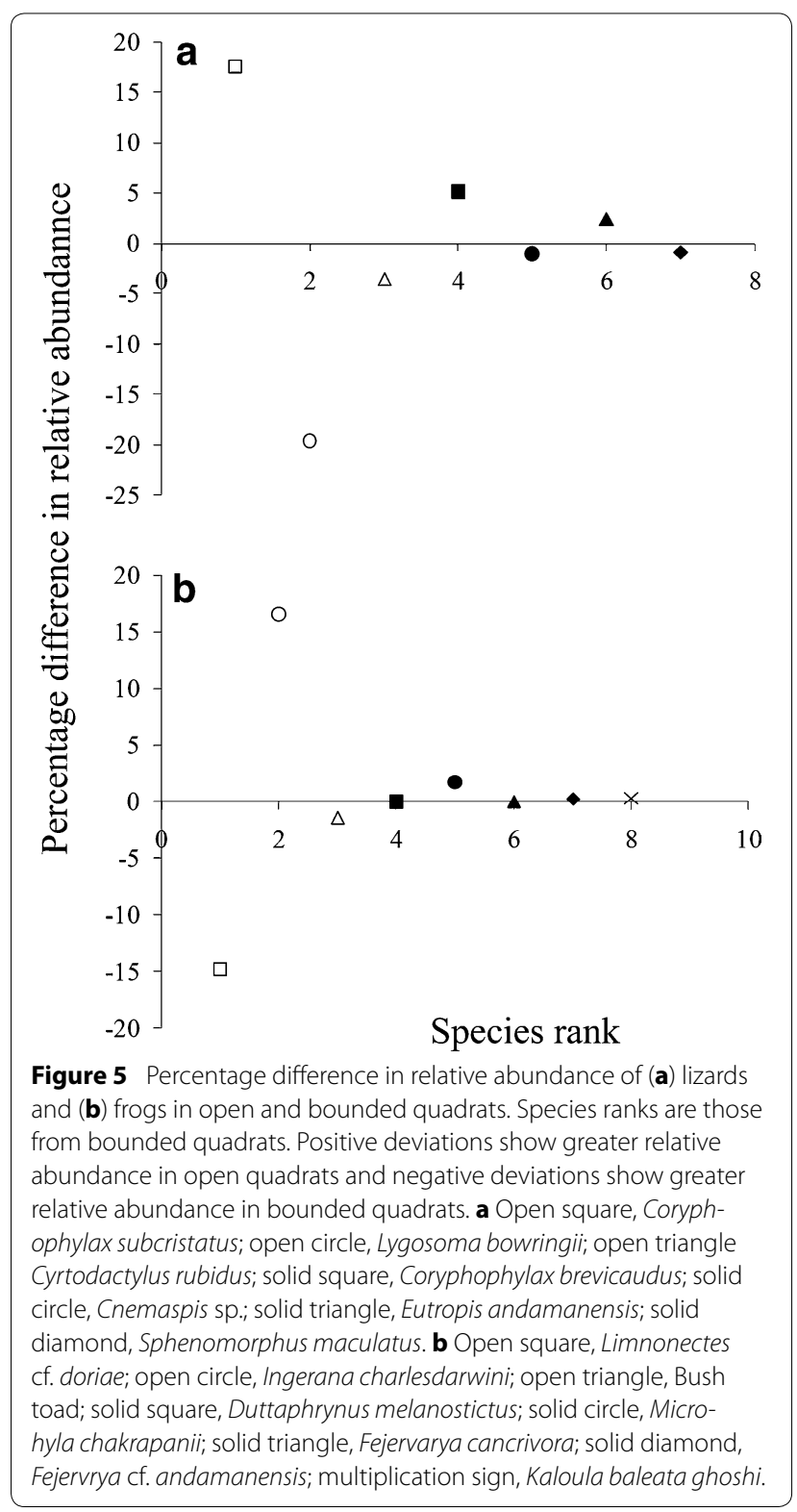

robust measures as they were not sensitive to the number of individuals included in the samples. Intensive sampling influenced measures of relative abundance of species and thereby altered community structure. Relative bias and precision point at high overall efficiency of bounded quadrats. We anticipate that our findings would prompt more field ecologists to consider careful selection of methods, analyses of data, and comparison of results from past studies. A promising direction of further research is the use of bounded quadrats for calibration of estimates obtained from other less intensive sampling methods [26]. This would pave way for developing new and more efficient sampling methods suitable for use in the tropics. At present, there is no 
alternative to an intensive sampling method to obtain precise or unbiased estimates of abundance and species richness of herpetofauna in tropical areas. We emphasize the need for refinement in sampling techniques so that credible findings strengthen tropical conservation.

\section{Methods}

Forest-floor herpetofaunal community is usually sampled using litter plots or quadrats demarcated on the ground [27-29]. This method assumes that all or most individuals within the quadrat are detected without any error in sampling [13]. This assumption is often flouted, as the quadrats are not fenced (hereafter referred to as 'open quadrats' or OQ), and many individuals escape or remain undetected. Fenced quadrats (hereafter referred to as 'bounded quadrats' or $\mathrm{BQ}$ ) prevent escape during sampling thereby capture large number of animals $[13,19,22$, 26].

\section{Study area}

The Andaman and Nicobar Islands consist of 556 islands, islets and rocks in the Bay of Bengal (Figure 6). These islands are part of a north south running submerged mountain chain from the ArakanYoma of Myanmar to the Mentawei Islands near Sumatra, Indonesia and show distinct biogeographic affinities [30-32]. Annual rainfall in these islands exceeds $3,000 \mathrm{~mm}$, and the dominant vegetation types are wet evergreen, semi evergreen and mangrove forests [33]. For a general description of these islands and their herpetofauna, see Das [31]. We sampled 15 islands in the Andaman Islands covering a large range of island areas.

\section{Sampling design}

The evergreen forests of Andaman Islands are generally of low elevation and gentle slope [34], and in order to avoid variation in estimates due to different site characteristics, we restricted sampling to elevations between 0 and $275 \mathrm{~m}$ asl with mean elevation of all quadrats being $74 \pm 5 \mathrm{~m}$. For all quadrat sampled We recorded the following microhabitat variables: forest type (Wet evergreen or WEG, Secondary evergreen or SEG, and Littoral evergreen or LEG), elevation in meters, number of trees with gbh $>20 \mathrm{~cm}$, number of trees with buttress roots, and canopy cover in percentage (Additional file 1). We sampled 151 open quadrats (OQ) and 49 bounded quadrats (BQ) during the relatively dry season that lasts from November to May, between 2010-2011 and 2011-2012 (Additional file 2). No quadrats were sampled during the wet season due to logistical difficulties in conducting field work during that period in these islands (Figure 6) (Additional file 3).

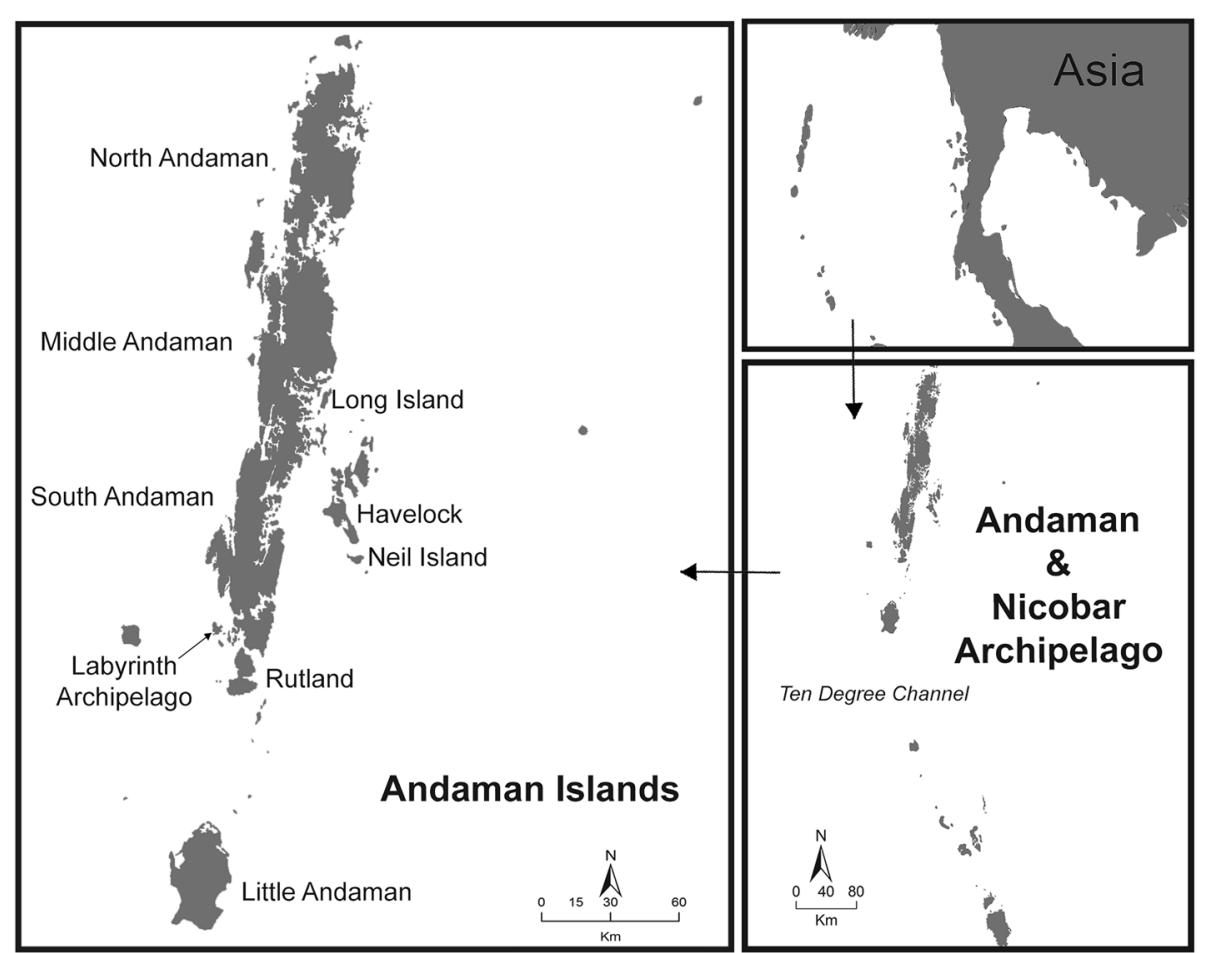

Figure 6 The Andaman Islands. The labyrinth Archipelago has 15 small islands, among which eight were sampled during this study. This map was made by S. Harikrishnan. 
We placed OQ $(10 \mathrm{~m} \times 10 \mathrm{~m})$ randomly in evergreen forest in all islands. They were demarcated with a nylon rope and four pegs at the four corners. Four to five people searched these quadrats following standard procedure $[5,6,27]$. We sampled 151 such quadrats. We counted individuals that escaped the quadrat before capture, but these records were used only in the calculation of overall densities and not for species richness and diversity estimates because it was not possible to identify such individuals to species level without closer examination. In order to compare the bias and precision of $\mathrm{OQ}$ in sampling forest floor herpetofauna, we also sampled BQ of the same dimension, in the same sites where $\mathrm{OQ}$ were sampled. We could not place these quadrats randomly because of uneven terrain, hard or rocky substrate, or large fallen tree trunks. We placed $\mathrm{BQs}$ in rainforests with relatively flat terrain (all quadrats below $270 \mathrm{~m}$ elevation) devoid of large fallen trees and large rocks $[9,13]$. However, care was taken to place them in similar habitats as OQ in order to reduce variation due to differences in habitat characteristics and within an island site, all BQ were placed within the general area covered by all the $O Q$ in that island site. Because of the disturbance created in sampling a single quadrat, a minimum distance of $50 \mathrm{~m}$ was maintained between all quadrats (OQ and $B Q)$. Our $B Q$ differed from Rodda et al. [13, 19], in that we used a $0.5 \mathrm{~m}$ high plastic sheet with its bottom buried in soil. We did not grease the top of the sheet, as our study area had only two species of lizards with expanded subdigital lamellae, which were arboreal species, and were recorded rarely within quadrats. Once established, we detached the top of the plastic sheet from the supporting stakes, so that it fell flat on the ground and left it undisturbed for about $24 \mathrm{~h}$. The following day, we approached the quadrat from four sides and quickly raised the plastic sheet, securing the top edge to the stakes so that no animals escaped. We sampled within the BQ following Rodda et al. [13], with the exception that we did not remove trees. Instead, we applied a broad strip of smooth duct tape around the trunk of trees at a height of $2 \mathrm{~m}$ from the ground, which effectively prevented all lizards other than two species with expanded sub-digital lamellae from arboreal escape. We captured all arboreal agamid lizards in the quadrats using a fishing line noose at the beginning of the quadrat search. We scanned tree trunks up to a height of $2 \mathrm{~m}$ and captured all frogs and lizards resting on top of or under the bark of trees.

\section{Data analysis}

We pooled the data from all islands for estimating species richness and density. Therefore, the densities reported here are average densities across the Andaman Islands. First, we explored the differences between OQ and BQ in environmental variables through boxplots. We also explored the effect of these variables and the types of quadrats on number of individuals detected in quadrats through General Linear Models (GLM) using an Analysis of Covariance (ANCOVA). In this analysis, number of individuals detected was used as response variable and quadrat type (OQ and $B Q$ ), forest type (WEG, SEG and LEG), elevation, number of trees, number of trees with buttresses and canopy cover were used as predictor variables. We also explored the effect of observer effect on number of individuals and species detected in OQ and BQ by plotting the effort (in man-hours) against number individuals and species and testing for correlations. The significance of correlations was tested using Pearson's product moment correlation. To evaluate the relative efficiency of $\mathrm{OQ}$ and $\mathrm{BQ}$ in detecting rare species, we plotted the percentage of singletons against sample size [1]. A lower limit of species richness was estimated using Chao1 estimator using the classic formula [35]. For estimating true species richness through extrapolation, we used a second order Jackknife estimate. Comparison of Chao1 and Jackknife estimator was carried out for 47 and 42 samples for both categories of quadrats for lizards and frogs respectively. For a comparison of diversity estimates from OQ and BQ, we used Fisher's $\alpha$ measure estimated using equal number of randomly selected set of individuals for both OQ and BQ (757 lizards and 188 frogs each). The above analyses were performed using the software EstimateS Ver. 9.1.0 [36], using sampling with replacement and 10,000 iterations. Quadrats from three small islands, where no frogs were detected in any of the sampling strategies (VES or quadrats), were excluded from the calculation of density of frogs. We used Wilcoxon-Mann-Whitney test to assess the significance of difference in estimated densities between $\mathrm{OQ}$ and $\mathrm{BQ}$, as well as the difference in effort (measured as man-hours/ quadrat).

In order to examine the effect of sampling error on relative abundance of species, we calculated the percentage difference in relative abundance of a species, between $\mathrm{OQ}$ and $\mathrm{BQ}$. This was plotted against the rank of species in the community obtained from $B Q$. Positive values indicated that the species relative abundance was represented more in $\mathrm{OQ}$ than in $\mathrm{BQ}$, and negative values indicated the opposite. For exploring bias, we considered estimates from $\mathrm{BQ}$ to be very near to the true value $[13,19,26]$, so that bias was calculated as a ratio of estimate from OQ to estimate from BQ: a value of 1 indicated an unbiased estimate, while a value less than 1 indicated estimates biased low for OQ. The relative precision of sampling methods was estimated as a ratio of 
population variance, $\hat{\sigma}_{O Q}^{2} / \hat{\sigma}_{B Q}^{2}$ after adjusting for the difference in sample sizes. For density estimates, the population variance of $\mathrm{BQ}$ was adjusted using the formula $\hat{\sigma}_{B Q}^{2}=\left(1-\frac{n_{O Q}}{N}\right)\left(\hat{\sigma}^{2} / n_{O Q}\right)$ where, $\mathrm{N}=$ total number of potential quadrats, $\hat{\sigma}^{2}=$ initial estimate of population variance from $\mathrm{BQ}, \hat{\sigma}_{O Q}^{2}=$ population variance estimated from $\mathrm{OQ}, \hat{\sigma}_{B Q}^{2}=$ sample-size adjusted population variance estimated from $\mathrm{BQ}$, and $n_{O Q}=$ number of OQs. $\mathrm{N}$ was calculated from the cumulative area of all islands sampled. A value of 1 indicated no difference in precision. Values greater than 1 indicated lower relative precision of estimates from $\mathrm{OQ}$ than in $\mathrm{BQ}$. For comparing bias and precision of species richness, second order Jackknife estimate was used. These analyses were performed using R [37]. Three arboreal species, namely Gekko verreauxi, Hemidactylus platyurus and Pseudocalotes andamanensis, and snakes were occasionally recorded in quadrats, and were not included in these analyses.

\section{Availability of supporting data}

All the supporting data are included as additional files of the manuscript: Harikrishnan S, Karthikeyan V. Data from: The Devil is in the Detail: Estimating species richness, density, and relative abundance of tropical island herpetofauna. Dryad Digital Repository. doi:10.5061/dryad.88v79.

\section{Additional files}

Additional files 1: Abundance and species richness data of frogs in the Andaman Islands collected by using open quadrats and bounded quadrats.

Additional files 2: Abundance and species richness data of lizards in the Andaman Islands collected by using open quadrats and bounded quadrats.

Additional files 3: File containing details of abbreviations used and the names and areas of islands sampled.

\section{Abbreviations}

BQ: bounded quadrat; OQ: open quadrat

\section{Authors' contributions}

$\mathrm{HS}$ and KV conceived and designed the experiments. HS performed the field data collection. $\mathrm{HS}$ and $\mathrm{KV}$ analyzed the data and wrote the manuscript. Both authors read and approved the final manuscript.

\section{Author details}

'Wildlife Institute of India, Chandrabani, Dehra Dun 248001, Uttarakhand, India. ${ }^{2}$ Present Address: Laboratory for Conservation of Endangered Species, CSIR-Centre for Cellular and Molecular Biology, Pillar 162, PVNR Expressway, Hyderguda, Hyderabad 500048, Telangana, India.

\section{Acknowledgements}

This work was supported by Department of Science and Technology (DST), Government of India (Grant No. SR/SO/AS-08/2009). We thank Department of Forests and Wildlife, Andaman and Nicobar Islands, for providing necessary permits to conduct fieldwork in the Andaman and Nicobar Islands (File No. CWLW/WL/134/161). We are grateful to The Andaman and Nicobar
Environmental Team (ANET) for logistical support. For help in fieldwork in the Andaman Islands we thank Nitya Prakash Mohanty who collected part of the data, S. R. Chandramouli, Chetan Rao and our field assistants Saw Glen, Sebe Horo, Anand James Tirkey and Sudhir Kumar Ekka.

\section{Compliance with ethical guidelines}

\section{Competing interests}

The authors declare that they have no competing interests.

Received: 29 November 2014 Accepted: 26 May 2015

Published online: 26 June 2015

\section{References}

1. Lopez LCS, De Aguiar Fracasso MP, Mesquita DO, Palma ART, Riul P (2012) The relationship between percentage of singletons and sampling effort: a new approach to reduce the bias of richness estimates. Ecol Indic 14:164-169

2. Beck J, Schwanghart W (2010) Comparing measures of species diversity from incomplete inventories: an update. Methods Ecol Evol 1:38-44

3. Elphick CS (2008) How you count counts: the importance of methods research in applied ecology. J Appl Ecol 45:1313-1320

4. Greenwood JJD, Robinson RA (2006) Principles of sampling. In: Sutherland WJ (ed) Ecological census techniques: a handbook, 2nd edn. Cambridge University Press, New York, pp 11-86

5. Scott NJJ (1976) The abundance and diversity of the herpetofaunas of tropical forest litter. Biotropica 8:669-674

6. Inger RF (1980) Densities of floor-dwelling frogs and lizards in lowland forests of Southeast Asia and Central America. Am Nat 115:761-770

7. Inger RF (1980) relative abundances of frogs and lizards in forests of Southeast Asia. Biotropica 12:14-22

8. May RM (1980) Why are there fewer frogs and lizards in southeast Asia than in central America? Nature 287:105

9. Fauth JE, Crother Bl, Slowinski JB (1989) Elevational patterns of species richness, evenness, and abundance of the Costa Rican leaf-litter herpetofauna. Biotropica 21:178-185

10. Giaretta AA, Facure KG, Sawaya RJ, Meyer JHDM, Chemin N (1999) Diversity and abundance of litter frogs in a montane forest of southeastern Brazil: seasonal and altitudinal changes. Biotropica 31:669-674

11. Hofer U, Bersier L-F (2001) Herpetofaunal diversity and abundance in tropical upland forests of Cameroon and Panama. Biotropica 33:142-152

12. Schlaepfer MA, Gavin TA (2001) Edge effects on lizards and frogs in tropical forest fragments. Conserv Biol 15:1079-1090

13. Rodda GH, Campbell EWI, Fritts TH (2001) A high validity census technique for herpetofaunal assemblages. Herpetol Rev 32(1):24-30

14. Rodda GH, Dean-Bradley K (2002) Excess density compensation of island herpetofaunal assemblages.J Biogeogr 29:623-632

15. Inger RF (2003) Sampling Biodiversity in Bornean Frogs. Nat Hist 3(April):9-15

16. Huang CY, Hou PCL (2004) Density and diversity of litter amphibians in a monsoon forest of southern Taiwan. Zool Stud 43:795-802

17. Van Sluys M, Vrcibradic D, Alves MAS, Bergallo HG, Rocha CFD (2007) Ecological parameters of the leaf-litter frog community of an Atlantic Rainforest area at Ilha Grande, Rio de Janeiro state, Brazil. Austral Ecol 32:254-260

18. Vasudevan K, Kumar A, Noon BR, Chellam R (2008) Density and diversity of forest floor anurans in the rain forests of southern Western Ghats, India. Herpetologica 64:207-215

19. Rodda GH, Perry G, Rondeau RJ, Lazell J (2001) The densest terrestrial vertebrate. J Trop Ecol 17(2):331-338

20. Kellner KF, Swihart RK (2014) Accounting for imperfect detection in ecology : a quantitative review. PLoS One 9(10):e111436

21. Rocha CFD, Van Sluys M, Alves MAS, Bergallo HG, Vrcibradic D (2001) Estimates of forest floor litter frog communities: a comparison of two methods. Austral Ecol 26:14-21

22. Heatwole H, Stuart BL (2008) High Densities of a "Rare" Skink. Herpetol Rev 39:169-170 
23. Allmon WD (1991) A plot study of forest floor litter frogs, Central Amazon, Brazil. JTrop Ecol 7:503-522

24. Vonesh JR (2001) Patterns of richness and abundance in a tropical African leaf-litter herpetofauna. Biotropica 33:502-510

25. Siqueira CC, Vrcibradic D, Almeida-gomes M, Borges-junior VNT, Almeidasantos P, Almeida-santos M et al (2009) Density and richness of leaf litter frogs (Amphibia : Anura) of an Atlantic Rainforest area in the Serra dos Órgãos, Rio de Janeiro State, Brazil. Africa (Lond) 26:97-102

26. Smolensky NL, Fitzgerald LA (2010) Distance sampling underestimates population densities of dune-dwelling lizards. J Herpetol 44:372-381

27. WC B, Ac A (1961) Populations of amphibians and reptiles in the submontane and montane forests of Cuernos de Negros, Philippine islands. Ecology 42:628-636

28. Bell KE, Donnelly MA (2006) Influence of forest fragmentation on community structure of frogs and lizards in northeastern Costa Rica. Conserv Biol 20:1750-1760

29. Lloyd M, Inger RF, King FW (1968) On the diversity of reptile and amphibian species in a Bornean rain forest. Am Nat 102:497-515

30. Rodolfo KS (1969) Bathymetry and marine geology of the andaman basin, and tectonic implications for Southeast Asia. Geol Soc Am Bull 80(July):1203-1230

31. Das I (1999) Biogeography of the amphibians and reptiles of the Andaman and Nicobar Islands, India. In: Ota H (ed) Tropical Island Herpetofauna Origin, Current Diversity, and Conservation. Elsevier Science B. V, Amsterdam, pp 43-77
32. Harikrishnan S, Vasudevan K, Choudhury BC (2010) A review of herpetofaunal descriptions and studies from Andaman and Nicobar Islands, with an updated checklist. In: Ramakrishna, Raghunathan C, Sivaperuman C (eds) Recent trends in biodiversity of Andaman \& Nicobar Islands. Zoological Survey of India, Kolkata, pp 387-398

33. ANONYMOUS (2009) India State of Forest Report. Forest Survey of India, Dehradun, $\mathrm{p} 199$

34. Champion HG, Seth SK (1968) A revised survey of the forest types of India. Natraj Publishers, Publication Division, Dehradun, p 404

35. Chao A (1984) Nonparametric estimation of the number of classes in a population. Scand J Stat 11:265-270

36. Colwell RK (2013) EstimateS: Statistical estimation of species richness and shared species from samples. http://viceroy.eeb.uconn.edu/estimates/ index.html. Accessed 17 Aug 2014

37. Team RC (2013) R: a language and environment for statistical computing. http://www.r-project.org/. Accessed 17 Aug 2014

\section{Submit your next manuscript to BioMed Central and take full advantage of:}

- Convenient online submission

- Thorough peer review

- No space constraints or color figure charges

- Immediate publication on acceptance

- Inclusion in PubMed, CAS, Scopus and Google Scholar

- Research which is freely available for redistribution

Submit your manuscript at

www.biomedcentral.com/submit

() Biomed Central 